\title{
TECNOLOGIAS EDUCACIONAIS E A FORMAÇÃO DOCENTE NO CONTEXTO DA EDUCAÇÃO PROFISSIONAL E TECNOLÓGICA
}

\author{
Dione Mari Caetano*, Flavia Heloisa Da Silva, Simone Urnauer, Ernani Viriato De Melo \\ Universidade Federal do Paraná \\ DOI: 10.15628/rbept.2019.8022
}

Artigo submetido em dez/2018 e aceito em ago/2019

\begin{abstract}
RESUMO
Este estudo se propõe a analisar a produção científica que contempla a temática da formação docente e das tecnologias educacionais na Educação Profissional e Tecnológica no período de 2010 a 2018. A pesquisa bibliográfica permitiu revelar que, na maioria dos trabalhos, depreende-se que o uso das tecnologias educacionais reivindica e está intrinsecamente relacionado com a necessária formação dos professores da Educação Profissional e Tecnológica. Trazer a discussão acerca das tecnologias educacionais para o reconhecimento de seu caráter histórico-social, tanto na formação discente quanto docente, contribui para a compreensão de que a tecnologia não é neutra, mas sim, carrega consigo intencionalidades, ao passo que, entendida desta forma, sua compreensão caminha em direção a uma formação humana integral e emancipatória.
\end{abstract}

Palavras-Chave: tecnologias educacionais. Educação Profissional e Tecnológica. Formação de professores.

\section{EDUCATIONAL TECHNOLOGIES AND TEACHER TRAINING IN THE CONTEXT OF PROFESSIONAL AND TECHNOLOGICAL EDUCATION}

\begin{abstract}
This study intends to analyze the scientific production that contemplates the theme of teacher education and educational technologies in Professional and Technological Education from 2010 to 2018. The bibliographic research has revealed that in most of the works, it is clear that the use of educational technologies claims and is intrinsically related to the necessary training of Technological and Professional Education teachers. Bringing the discussion of educational technologies to the recognition of their historical and social character, both in student and teacher training, contributes to the understanding that technology is not neutral, but rather carries with it intentions, while understood in this way, It is understanding moves towards an integral and emancipatory human formation.
\end{abstract}

Keywords: educational technologies. Professional and Technological Education. Teacher training. 


\title{
1 INTRODUÇÃO
}

Tratar das tecnologias educacionais implica em analisar, inicialmente, o conceito de tecnologia e como ele se constrói no contexto educacional. Para tanto, Quartiero, Lunardi e Bianchetti (2010) partem de dois pressupostos para compreender os conceitos de técnica e tecnologia e sua apropriação histórica no campo da educação. O primeiro deles diz respeito a estreita relação entre o modo de produção e o consequente modo de educação vinculado. O segundo, por sua vez, conforme os autores,

\begin{abstract}
liga-se à ideia de que cada vez que a educação, e, em especial, a educação profissional, preserva a norma que valoriza a contínua mudança tecnológica, reitera os discursos que supervalorizam a atual "era tecnológica", e, assim fazendo, fortalece a lógica pragmática e utilitarista e a suposta neutralidade da tecnologia. (QUARTIERO; LUNARDI; BIANCHETTI, 2010, p. 286)
\end{abstract}

Assim sendo, trata-se de partir da constatação de que, para os autores, a educação escolar em si é tecnológica, já que ela envolve a invenção de suas formas simbólicas, assim como suas tecnologias organizacionais e instrumentais. Em outros termos, nas diferentes etapas da história da educação, a tecnologia se fez presente e cada vez mais aparece nos processos de ensino e aprendizagem.

O uso da tecnologia digital em sala, por exemplo, rompe com a forma tradicionalmente linear e sequencial, estruturada e previsível de transmissão de conhecimento, tendo em vista que o tempo do conhecimento tecnológico é plural, onde as informações são acessadas simultaneamente e de maneira anárquica, convergindo para alterações na relação social e consequentemente em todo o processo educacional (Kenski 2013, p.13).

No entanto, é necessário radicalizar o comportamento e as práticas pedagógicas para se obter a cultura tecnológica, não sendo possível a implantação desta somente com a incorporação de mídias digitais no ensino. De acordo com Kenski (2013, p.68) "há um grande abismo entre o ensino mediado pelas TICs - praticado em muitas das escolas, universidades, faculdades - e os processos dinâmicos que podem acontecer nas relações entre professores e alunos online".

Desta forma, atualmente, tem-se abordado sobre o papel social da escola e sobre ele o impacto das constantes mudanças tecnológicas, onde a tecnologia ora opositiva, ora conectiva, afeta as relações sociais.

Para tanto, Quartiero, Lunardi e Bianchetti (2010, p. 295), alertam sobre o distanciamento do conceito de tecnologia de quem o produz, ou seja, "torna-se cada vez mais difícil atribuir origem humana - inteligência humana objetivada - à tecnologia que permeia nossa sociedade", ou seja, distancia-se do elemento humano ao qual está atrelado a tecnologia.

No ambiente escolar, a relação de oposição humano/máquina originária do desenvolvimento tecnológico é ambígua, ora apresentando-se como elo em um plano social distinto, onde as pessoas apesar de distantes 
geograficamente, se conectam virtualmente, abrindo portas para novas situações de aprendizagem, novas formas de aquisição de conhecimento e relacionamentos formativos, ora causando um esvaziamento das relações sociais presenciais, um isolamento mesmo em meio a outros.

Trazer a complexidade que circunda as tecnologias educacionais, suas relações e seus desafios para o campo da atuação docente, pressupõe também que se analise como se dá seu debate na formação docente, sobretudo, na Educação Profissional e Tecnológica, ao que se compreende que,

as tecnologias não podem ser vistas apenas como aplicações da ciência, mas como construções sociais decorrentes da forma de organização econômica e política das sociedades e, portanto, estreitamente relacionadas com as respectivas culturas. (MOURA, 2014, p. 102)

A formação de professores para a Educação Profissional e Tecnológica é um campo que reivindica estudos que possam superar sua histórica forma emergencial, improvisada, bem como a ausência de discussões que contemplem a dualidade histórica presente na educação brasileira e que tragam as relações trabalho e educação e sobre elas a construção de um olhar crítico sobre a tecnologia. Assim como a Freire (1994, p. 32) que não diviniza a tecnologia, tampouco a diaboliza, mas "a olha ou mesmo a espreita de forma criticamente curiosa", ou seja, não a nega, tratase de considerar que seu olhar na formação docente, envolta em contradições e transformações, necessita considerar que "ensinar exige criticidade" (FREIRE, 1994, p. 31).

Romper com a face instrumental e utilitarista da tecnologia e seu discurso instrucional, reivindica compreender criticamente como o debate sobre as tecnologias educacionais está sendo desenvolvido no contexto da educação profissional e tecnológica. Nesta pesquisa, questiona-se: qual é a discussão que vem sendo feita nas produções científicas que envolvam as tecnologias educacionais e a formação docente atreladas à educação profissional e tecnológica?

\section{PROCEDIMENTOS METODOLÓGICOS}

Este estudo propõe uma revisão sistemática da literatura, no período de 2010 a 2018, que discute a formação docente e o uso das tecnologias educacionais trazendo-as para o contexto da Educação Profissional e Tecnológica (EPT). Trata-se do desvelar sobre como a temática tem sido abordada na produção científica a partir do recorte proposto, oportunizando seu aprofundamento teórico e verificando o viés dado a partir da análise de investigações que se desenvolveram nos últimos 8 anos.

Para isso, foi realizado o levantamento de artigos nacionais localizados na plataforma de busca Google Acadêmico de maior relevância. $O$ refinamento da amostra se fez utilizando a busca pelos termos "tecnologias 
educacionais", "educação profissional e tecnológica" e "formação docente", sendo que os três termos deveriam constar no documento, de forma a serem descartados os documentos que não se enquadrem nesta descrição. Ao final, utilizando-se dos critérios estabelecidos, foram selecionados os 15 artigos científicos abrangendo dissertações, periódicos e anais de eventos.

\section{RESULTADOS E DISCUSSÕES}

No quadro abaixo apresentamos a caracterização do resultado das buscas realizadas na plataforma Google Acadêmico, utilizando simultaneamente os termos "tecnologias educacionais", "educação profissional e tecnológica" e "formação docente", em que constam os seguintes dados: título do trabalho, objetivos, procedimentos metodológicos e principais resultados.

Em seguida, são apresentadas as discussões que integram o corpus da análise e que contemplam os vieses das investigações no campo da educação profissional e tecnológica.

\section{QUADRO 1 - DADOS DOS TRABALHOS SELECIONADOS - PERÍODO DE $2010-2018$}

\begin{tabular}{|c|c|c|c|}
\hline Título & Objetivos & $\begin{array}{l}\text { Procedimentos } \\
\text { Metodológicos }\end{array}$ & Principais Resultados \\
\hline $\begin{array}{l}\text { Webquest }{ }^{1} \text { na } \\
\text { formação } \\
\text { continuada de } \\
\text { professores da } \\
\text { Educação } \\
\text { Profissional e } \\
\text { Tecnológica } \\
\text { (VIANA NETO; } \\
\text { SARMENTO, } \\
\text { 2018) }\end{array}$ & $\begin{array}{l}\text { Objetivo de } \\
\text { responder } \\
\text { à seguinte } \\
\text { questão: Como } \\
\text { as pesquisas } \\
\text { mais recentes } \\
\text { têm discutido o } \\
\text { uso da WebQuest } \\
\text { no processo } \\
\text { de formação } \\
\text { continuada } \\
\text { de professores } \\
\text { da Educação } \\
\text { Profissional } \\
\text { e Tecnológica } \\
\text { (EPT). }\end{array}$ & $\begin{array}{l}\text { Revisão de } \\
\text { literatura da } \\
\text { produção } \\
\text { acadêmica } \\
\text { compreendendo o } \\
\text { período de } 2013 \text { à } \\
2017 \text {, através do } \\
\text { Portal SCIELO } \\
\text { (Scientific } \\
\text { Electronic Library } \\
\text { Online); Portal de } \\
\text { Periódicos da } \\
\text { CAPES } \\
\text { (Coordenação } \\
\text { Aperfeiçoamento de } \\
\text { Pessoal de Nível } \\
\text { Superior); } \\
\text { Biblioteca Digital } \\
\text { Brasileira de Teses } \\
\text { e Dissertações } \\
\text { (BDTD). Pesquisa } \\
\text { de caráter quali- } \\
\text { quantitativo }\end{array}$ & $\begin{array}{l}\text { Como resultados, não foram } \\
\text { localizados trabalhos que tratassem } \\
\text { especificamente } \\
\text { do uso da WebQuest na formação } \\
\text { continuada do professor da EPT. } \\
\text { Além disso, a WebQuest pode } \\
\text { auxiliar o docente no planejamento } \\
\text { e problematização de sua prática } \\
\text { pedagógica. }\end{array}$ \\
\hline $\begin{array}{l}\text { O uso da lousa } \\
\text { digital interativa }\end{array}$ & $\begin{array}{l}\text { Identificar a } \\
\text { formação docente }\end{array}$ & $\begin{array}{l}\text { Pesquisa } \\
\text { descritiva com }\end{array}$ & $\begin{array}{l}\text { O estudo confirma que os } \\
\text { professores da instituição }\end{array}$ \\
\hline
\end{tabular}

\footnotetext{
${ }^{1}$ WebQuest "ferramenta com propósitos de orientar a busca de conhecimentos, em que parte ou todas as informações lá constantes e colocadas à disposição do estudante provêm da internet, previamente organizadas" (Dodge, 1995 apud Viana Neto e Sarmento, 2018, p. 03)
} 


\begin{tabular}{|c|c|c|c|}
\hline $\begin{array}{l}\text { pelos docentes de } \\
\text { um Instituto } \\
\text { Federal (SC) } \\
\text { (TREVISOL; } \\
\text { CRESCÊNCIO; } \\
\text { DOMINGUES, } \\
2016 \text { ) }\end{array}$ & $\begin{array}{l}\text { e o uso da lousa } \\
\text { digital interativa } \\
\text { como método de } \\
\text { ensino- } \\
\text { aprendizagem em } \\
\text { um Instituto } \\
\text { Federal (IF) de } \\
\text { Santa Catarina. }\end{array}$ & $\begin{array}{l}\text { levantamento de } \\
\text { dados, com análise } \\
\text { descritiva dos } \\
\text { dados, a partir da } \\
\text { aplicação de um } \\
\text { questionário com } \\
\text { perguntas fechadas } \\
\text { a } 132 \text { professores } \\
\text { do IFSC }\end{array}$ & $\begin{array}{l}\text { investigada não receberam } \\
\text { formação para o uso da lousa digital } \\
\text { interativa como ferramenta de } \\
\text { ensino-aprendizagem, entretanto a } \\
\text { maioria dos docentes sinaliza que } \\
\text { tal prática é necessária. }\end{array}$ \\
\hline $\begin{array}{l}\text { O uso de recursos } \\
\text { tecnológicos para } \\
\text { o ensino de } \\
\text { Língua } \\
\text { Portuguesa: } \\
\text { proposta de } \\
\text { utilização do } \\
\text { Software AntConc } \\
\text { (SILVA; COELHO, } \\
\text { 2017) }\end{array}$ & $\begin{array}{l}\text { O objetivo do } \\
\text { trabalho é } \\
\text { demonstrar as } \\
\text { contribuições e } \\
\text { as funções do } \\
\text { software } \\
\text { AntConc no } \\
\text { ensino da Língua } \\
\text { Portuguesa, a } \\
\text { partir da } \\
\text { Aprendizagem } \\
\text { Movida por } \\
\text { Dados }\end{array}$ & $\begin{array}{l}\text { Estudo de natureza } \\
\text { qualitativa e } \\
\text { exploratória com } \\
\text { entrevista semi- } \\
\text { estruturada, } \\
\text { roteirizada, } \\
\text { contendo } 6 \\
\text { questões, aplicada } \\
\text { em } 2 \text { professoras, } \\
\text { sendo uma do } \\
\text { ensino fundamental } \\
\text { e outra do ensino } \\
\text { médio de escolas } \\
\text { diferentes nos } \\
\text { arredores de } \\
\text { Manaus - AM }\end{array}$ & $\begin{array}{l}\text { O uso de recursos } \\
\text { tecnológicos, tomando como } \\
\text { exemplo a ferramenta AntConc, a } \\
\text { partir da Aprendizagem Movida por } \\
\text { Dados pode promover novas } \\
\text { práticas e posturas tanto do } \\
\text { estudante, oportunizando motivação } \\
\text { e engajamento, } \\
\text { quanto do professor, evidenciando } \\
\text { a importância de se promover a } \\
\text { autonomia e o protagonismo do } \\
\text { aluno. Para tanto, é necessário que } \\
\text { o docente saiba utilizar a ferramenta } \\
\text { e conheça os pressupostos teóricos } \\
\text { da Aprendizagem Movida por } \\
\text { Dados. }\end{array}$ \\
\hline $\begin{array}{l}\text { Aprendizagem } \\
\text { móvel: percepções } \\
\text { quanto à utilização } \\
\text { por docentes da } \\
\text { educação } \\
\text { profissional e } \\
\text { tecnológica } \\
\text { (FREITAS; } \\
\text { DUARTE FILHO, } \\
\text { 2018) }\end{array}$ & $\begin{array}{l}\text { Verificar se os } \\
\text { professores da } \\
\text { EPT utilizam (e } \\
\text { de que forma) a } \\
\text { aprendizagem } \\
\text { móvel. }\end{array}$ & $\begin{array}{l}\text { Pesquisa } \\
\text { exploratória de } \\
\text { natureza aplicada } \\
\text { com abordagem } \\
\text { quali-quantitativa } \\
\text { utilizando como } \\
\text { instrumento de } \\
\text { coleta de dados a } \\
\text { pesquisa } \\
\text { bibliográfica e } \\
\text { aplicação de } \\
\text { questionário com } \\
21 \text { questões } \\
\text { abertas e fechadas, } \\
\text { aplicadas via } \\
\text { Google Forms em } \\
20 \text { professores da } \\
\text { EPT }\end{array}$ & $\begin{array}{l}\text { Os resultados demonstraram que a } \\
\text { maioria dos docentes usa } \\
\text { tecnologias móveis para fins } \\
\text { educacionais, por iniciativa própria, } \\
\text { dentro e fora do horário escolar. } \\
\text { Algumas dificuldades foram } \\
\text { apresentadas, como acesso à } \\
\text { internet e falta de } \\
\text { capacitação. Concluiu-se que } \\
\text { gradual e informalmente, a } \\
\text { aprendizagem móvel está sendo } \\
\text { inserida no contexto da } \\
\text { EPT. }\end{array}$ \\
\hline $\begin{array}{l}\text { Os recursos } \\
\text { tecnológicos } \\
\text { utilizados pelos } \\
\text { alunos do PEG } \\
\text { (WEIZENMANN; } \\
\text { JARDIM; ROCHA, } \\
2014 \text { ) }\end{array}$ & $\begin{array}{l}\text { Verificar os } \\
\text { recursos } \\
\text { tecnológicos } \\
\text { utilizados pelos } \\
\text { alunos do } \\
\text { Programa } \\
\text { Especial de } \\
\text { Graduação de } \\
\text { Formação de } \\
\text { Professores para } \\
\text { Educação } \\
\text { Profissional } \\
\text { (PEG) }\end{array}$ & $\begin{array}{l}\text { Pesquisa } \\
\text { Qualitativa com } \\
\text { investigação } \\
\text { empírica e } \\
\text { aplicação de } \\
\text { questionário como } \\
\text { instrumento de } \\
\text { coleta de dados } \\
\text { contendo } 8 \\
\text { questões fechadas, } \\
\text { aos estudantes do } \\
\text { terceiro semestre } \\
\text { do Programa } \\
\text { Especial de } \\
\text { Formação de } \\
\text { Professores } \\
\text { para Educação } \\
\text { Profissional }\end{array}$ & $\begin{array}{l}\text { A pesquisa aponta que os } \\
\text { equipamentos mais utilizados são os } \\
\text { notebooks, celulares-smartphone, } \\
\text { desktop } \\
\text { e tablet, como meio alternativo para } \\
\text { acesso à internet, com a maior } \\
\text { frequência de uso para as redes } \\
\text { sociais, as contas de e-mail, os } \\
\text { livros digitais e os vídeos. } \\
\text { Desta forma, constatou-se que } \\
\text { existe a utilização de recursos } \\
\text { tecnológicos para o público } \\
\text { pesquisado, contudo, insuficiente } \\
\text { para suprimir as necessidades que a } \\
\text { educação tecnológica exige. }\end{array}$ \\
\hline A organização da & Analisar a & Pesquisa qualitativa & A função dos docentes envolvidos \\
\hline
\end{tabular}




\begin{tabular}{|c|c|c|c|}
\hline $\begin{array}{l}\text { docência coletiva } \\
\text { no contexto da } \\
\text { educação a } \\
\text { distância: o uso } \\
\text { das tecnologias de } \\
\text { informação e } \\
\text { comunicação e a } \\
\text { ação pedagógica } \\
\text { (SOUZA; JARDIM, } \\
\text { 2018) }\end{array}$ & $\begin{array}{l}\text { organização do } \\
\text { trabalho docente, } \\
\text { considerando o } \\
\text { contexto da } \\
\text { Educação a } \\
\text { Distância, do } \\
\text { Curso de Pós- } \\
\text { Graduação "lato } \\
\text { sensu", em } \\
\text { Informática na } \\
\text { Educação, } \\
\text { ofertado pelo } \\
\text { Centro de } \\
\text { Referência em } \\
\text { Formação e } \\
\text { Educação a } \\
\text { Distância } \\
\text { (CEAD), no } \\
\text { âmbito do } \\
\text { Instituto Federal } \\
\text { do Norte de } \\
\text { Minas Gerais } \\
\text { (IFNMG) }\end{array}$ & $\begin{array}{l}\text { bibliográfica e } \\
\text { observacional da } \\
\text { prática coletiva } \\
\text { dos professores e } \\
\text { dos tutores do } \\
\text { Curso de Pós- } \\
\text { Graduação } \\
\text { "lato sensu", em } \\
\text { Informática na } \\
\text { Educação, ofertado } \\
\text { pelo CEAD, no } \\
\text { IFNMG, no período } \\
\text { de junho de } 2014 \text { a } \\
\text { junho de } 2015 . \\
\text { Com aplicação de } \\
\text { questionário } \\
\text { contendo questões } \\
\text { abertas. }\end{array}$ & $\begin{array}{l}\text { no espaço de construção de } \\
\text { conhecimentos necessita ser } \\
\text { analisada sob o ponto de vista da } \\
\text { oferta de cursos com qualidade. } \\
\text { Mesmo com tantos recursos } \\
\text { tecnológicos, carece de profissionais } \\
\text { qualificados para a utilização } \\
\text { adequada dos recursos disponíveis, } \\
\text { com prática docente compartilhada, } \\
\text { numa comunicação mais } \\
\text { participativa e organizada do grupo. }\end{array}$ \\
\hline $\begin{array}{l}\text { Educação } \\
\text { tecnológica e } \\
\text { formação docente: } \\
\text { saberes e práticas } \\
\text { em foco (LEMOS; } \\
\text { VIEIRA, 2010) }\end{array}$ & $\begin{array}{l}\text { Identificar a } \\
\text { importância da } \\
\text { educação } \\
\text { tecnológica para } \\
\text { a formação de } \\
\text { professores e os } \\
\text { saberes } \\
\text { mobilizados em } \\
\text { sua prática. }\end{array}$ & $\begin{array}{l}\text { Pesquisa } \\
\text { bibliográfica } \\
\text { fundamentada em } \\
\text { pesquisadores que } \\
\text { apresentaram } \\
\text { trabalhos no } \\
\text { GT } 08 \text { do } 31^{\circ} \\
\text { Encontro da Anped } \\
\text { e em autores } \\
\text { que tratam da } \\
\text { formação docente e } \\
\text { processos } \\
\text { educativos na } \\
\text { Educação } \\
\text { Tecnológica. }\end{array}$ & $\begin{array}{l}\text { Ao buscar compreender os saberes } \\
\text { e as práticas docentes na educação } \\
\text { tecnológica, as autoras } \\
\text { compreendem pela contribuição do } \\
\text { estudo ao permitirem a reflexão } \\
\text { acerca da temática, sobre a } \\
\text { importância de momentos de } \\
\text { formação através de relatos de } \\
\text { experiência, oficinas, grupos de } \\
\text { trabalho, e em um âmbito mais } \\
\text { amplo de políticas públicas voltadas } \\
\text { à formação de professores. }\end{array}$ \\
\hline $\begin{array}{l}\text { A formação de } \\
\text { professores para a } \\
\text { Educação } \\
\text { Profissional nos } \\
\text { Institutos Federais } \\
\text { (BRIGNONI; } \\
\text { PIRES, 2010) }\end{array}$ & $\begin{array}{l}\text { Analisar as } \\
\text { licenciaturas em } \\
\text { educação } \\
\text { profissional, } \\
\text { observando se } \\
\text { houve } \\
\text { crescimento } \\
\text { quantitativo da } \\
\text { oferta de } \\
\text { licenciatura nessa } \\
\text { modalidade de } \\
\text { ensino } \\
\text { e analisando a } \\
\text { matriz curricular } \\
\text { de um desses } \\
\text { cursos. }\end{array}$ & $\begin{array}{l}\text { Pesquisa } \\
\text { Bibliográfica com } \\
\text { análise documental } \\
\text { da matriz } \\
\text { curriculares do } \\
\text { curso de } \\
\text { Licenciatura em } \\
\text { Ciências Agrícolas, } \\
\text { ofertado pelo } \\
\text { Instituto Federal } \\
\text { Catarinense no } \\
\text { Campus de } \\
\text { Araquari. }\end{array}$ & $\begin{array}{l}\text { A licenciatura em educação } \\
\text { profissional ainda suscita muitos } \\
\text { questionamentos, além de estarem } \\
\text { ainda presentes medidas } \\
\text { emergenciais para a formação de } \\
\text { professores, necessitando, pois, a } \\
\text { formação de professores de } \\
\text { políticas públicas efetivas. }\end{array}$ \\
\hline $\begin{array}{l}\text { Interlocuções das } \\
\text { pesquisas em } \\
\text { tecnologias } \\
\text { na educação } \\
\text { (CONTE; } \\
\text { OURIQUE, 2018) }\end{array}$ & $\begin{array}{l}\text { O objetivo é } \\
\text { discutir acerca } \\
\text { dos sentidos e } \\
\text { significados das } \\
\text { tecnologias na } \\
\text { educação, e suas } \\
\text { novas }\end{array}$ & $\begin{array}{l}\text { Pesquisa } \\
\text { bibliográfica na } \\
\text { Biblioteca Digital } \\
\text { Brasileira de Teses } \\
\text { e Dissertações } \\
\text { (BDTD), das teses } \\
\text { produzidas nos }\end{array}$ & $\begin{array}{l}\text { A partir das teses produzidas nos } \\
\text { Programas de Pós-Graduação em } \\
\text { Educação de universidades públicas } \\
\text { brasileiras no triênio 2012-2014, as } \\
\text { produções analisadas evidenciam } \\
\text { uma necessidade de formação } \\
\text { profissional que discuta as }\end{array}$ \\
\hline
\end{tabular}




\begin{tabular}{|c|c|c|c|}
\hline & $\begin{array}{l}\text { manifestações na } \\
\text { atuação } \\
\text { pedagógica, bem } \\
\text { como as } \\
\text { transformações } \\
\text { provocadas no } \\
\text { entendimento dos } \\
\text { processos de } \\
\text { ensinar e } \\
\text { aprender. }\end{array}$ & $\begin{array}{l}\text { Programas de Pós- } \\
\text { Graduação em } \\
\text { Educação de } \\
\text { universidades } \\
\text { públicas brasileiras } \\
\text { no triênio 2012- } \\
2014 \text { através de a } \\
\text { uma perspectiva } \\
\text { hermenêutica } \\
\text { reconstrutiva. }\end{array}$ & $\begin{array}{l}\text { tecnologias educacionais, como } \\
\text { aporte para a interdisciplinaridade e } \\
\text { acesso às TIC. Entretanto, } \\
\text { fundamental se faz uma a } \\
\text { superação da utopia tecnocientífica } \\
\text { em que se verifica ações passivas e } \\
\text { acríticas. As autoras propõem a } \\
\text { compreensão dos sentidos e } \\
\text { significados das tecnologias da } \\
\text { educação que superem a visão } \\
\text { descritiva de práticas exitosas, para } \\
\text { uma interlocução crítica nos } \\
\text { processos pedagógicos. }\end{array}$ \\
\hline $\begin{array}{l}\text { Substâncias \& } \\
\text { Cotidiano: uma } \\
\text { proposta para o } \\
\text { ensino de ligações } \\
\text { químicas por meio } \\
\text { do enfoque } \\
\text { ciência, tecnologia } \\
\text { e sociedade in } \\
\text { Propostas de ação } \\
\text { para a formação } \\
\text { continuada de } \\
\text { professores da } \\
\text { educação } \\
\text { profissional e } \\
\text { tecnológica } \\
\text { (KOSCIANSKI; } \\
\text { SILVEIRA;SAUER } \\
\text {, 2016) }\end{array}$ & $\begin{array}{l}\text { Apresentar um } \\
\text { estudo em que se } \\
\text { desenvolveu } \\
\text { o ensino de } \\
\text { ligações químicas } \\
\text { por meio do } \\
\text { enfoque CTS } \\
\text { (Ciência, } \\
\text { Tecnologia e } \\
\text { Sociedade) a } \\
\text { partir de reflexões } \\
\text { sobre } \\
\text { substâncias e } \\
\text { cotidiano }\end{array}$ & $\begin{array}{l}\text { Pesquisa } \\
\text { qualitativa, } \\
\text { interpretativa } \\
\text { com observação } \\
\text { participante, } \\
\text { aplicada em } 42 \\
\text { alunos do } 2^{\circ} \text { ano do } \\
\text { ensino médio } \\
\text { técnico, em } 10 \\
\text { aulas de } 50 \text { minutos }\end{array}$ & $\begin{array}{l}\text { Este estudo levou a perceber que a } \\
\text { introdução ao conteúdo de química } \\
\text { numa abordagem CTS, por meio } \\
\text { dos temas sociais, pode contribuir } \\
\text { no processo de ensino e } \\
\text { aprendizagem de química, } \\
\text { preparando o estudante para } \\
\text { compreender as informações acerca } \\
\text { desta ciência, necessárias para a } \\
\text { sua participação efetiva na } \\
\text { sociedade tecnológica do seu dia a } \\
\text { dia. }\end{array}$ \\
\hline $\begin{array}{l}\text { Perfil e identidade } \\
\text { do tutor em cursos } \\
\text { na modalidade a } \\
\text { distância do IFAL } \\
\text { vinculados ao } \\
\text { Sistema } \\
\text { Universidade } \\
\text { Aberta do Brasil: } \\
\text { definições e } \\
\text { prática docente } \\
\text { (GOMES, 2010) }\end{array}$ & $\begin{array}{l}\text { Discutir o } \\
\text { conceito de } \\
\text { tutoria partindo } \\
\text { da formação da } \\
\text { palavra tutor e da } \\
\text { aplicação do seu } \\
\text { conceito em } \\
\text { educação a } \\
\text { distância } \\
\text { procurando } \\
\text { definir a prática } \\
\text { docente em EAD }\end{array}$ & $\begin{array}{l}\text { Pesquisa qualitativa } \\
\text { bibliográfica } \\
\text { utilizando as } \\
\text { incursões do IFAL } \\
\text { na Educação a } \\
\text { Distância no } \\
\text { período de } 2006 \text { à } \\
2009 .\end{array}$ & $\begin{array}{l}\text { Faz-se necessário uma releitura dos } \\
\text { modelos de educação, bem como } \\
\text { uma ressignificação dos agentes } \\
\text { envolvidos partindo da } \\
\text { compatibilidade de funções entre os } \\
\text { tutores e professores. } \\
\text { É necessário também, verificar os } \\
\text { distanciamentos e aproximações da } \\
\text { prática pedagógica entre tutores e } \\
\text { professores. } \\
\text { Na primeira instância de análise } \\
\text { compreende-se que a nomenclatura } \\
\text { tutoria, no que se concerne ao } \\
\text { serviço público de ensino, pode ser } \\
\text { uma estratégia política para } \\
\text { viabilização de cursos na } \\
\text { modalidade à distância em larga } \\
\text { escala, tornando esta carreira } \\
\text { docente diferenciada da modalidade } \\
\text { presencial. }\end{array}$ \\
\hline $\begin{array}{l}\text { As novas } \\
\text { tendências da } \\
\text { formação de } \\
\text { professores no } \\
\text { contexto } \\
\text { tecnológico } \\
\text { (ALVES, 2002) }\end{array}$ & $\begin{array}{l}\text { Focalizar as } \\
\text { tendências da } \\
\text { profissão do } \\
\text { professor e do } \\
\text { processo de } \\
\text { mudança na } \\
\text { transição do } \\
\text { século XX para o } \\
\text { século XXI }\end{array}$ & $\begin{array}{l}\text { Pesquisa qualitativa } \\
\text { bibliográfica. }\end{array}$ & $\begin{array}{l}\text { As principais mudanças foram: } \\
\text { O professor não pode } \\
\text { limitar-se a difusor do saber; } \\
\text { O professor deve organizar o saber } \\
\text { coletivo, em uma relação de } \\
\text { parceria com os alunos; } \\
\text { O professor deve questionar sua } \\
\text { prática pedagógica revendo } \\
\text { constantemente a linha de ação } \\
\text { docente, aprimorando sua prática } \\
\text { através de novos programas de } \\
\text { formação. }\end{array}$ \\
\hline
\end{tabular}




\begin{tabular}{|c|c|c|c|}
\hline $\begin{array}{l}\text { Formação } \\
\text { profissional em } \\
\text { Recursos } \\
\text { Educacionais } \\
\text { Abertos } \\
\text { (OLIVEIRA; } \\
\text { ABREU, GOMES, } \\
\text { 2015) }\end{array}$ & $\begin{array}{l}\text { Traçar um perfil } \\
\text { dos docentes } \\
\text { participantes do } \\
\text { Curso de } \\
\text { Recursos } \\
\text { Educacionais } \\
\text { Abertos (CREA) e } \\
\text { levantar os } \\
\text { requisitos de } \\
\text { ambientes e } \\
\text { ferramentas que } \\
\text { promovam uso e } \\
\text { adoção dos } \\
\text { Recursos } \\
\text { Educacionais } \\
\text { Abertos (REA) }\end{array}$ & $\begin{array}{l}\text { Pesquisa } \\
\text { exploratória } \\
\text { iniciando com uma } \\
\text { revisão bibliográfica } \\
\text { para seleção do } \\
\text { material de maior } \\
\text { adequabilidade. } \\
\text { Divulgação e } \\
\text { inscrição para o } \\
\text { curso nas redes } \\
\text { sociais por } 30 \text { dias, } \\
\text { através de } \\
\text { formulário } \\
\text { eletrônico, tendo } \\
\text { como público alvo } \\
\text { professores da rede } \\
\text { pública e privada, } \\
\text { totalizando } 16 \\
\text { inscritos no curso } \\
\text { de } 40 h \text {, distribuído } \\
\text { em } 20 \text { dias, na } \\
\text { modalidade à } \\
\text { distância. }\end{array}$ & $\begin{array}{l}\text { O uso das ferramentas online para } \\
\text { oferta do CREA favoreceu a } \\
\text { participação de professores dos } \\
\text { estados do Ceará e Pernambuco } \\
\text { A análise dos resultados do CREA, } \\
\text { então, tornou possível perceber o } \\
\text { interesse dos participantes do CREA } \\
\text { em usar ou adequar REAs e } \\
\text { Práticas Educacionais Abertas - } \\
\text { PEAs em seus ambientes laborais, } \\
\text { já que alguns partícipes conheciam } \\
\text { os conceitos, mas não trabalharam } \\
\text { com REAs e PEAs, enquanto outros } \\
\text { desconheciam tais possibilidades. }\end{array}$ \\
\hline $\begin{array}{l}\text { Políticas públicas } \\
\text { de formação } \\
\text { docente: o desafio } \\
\text { do direito à } \\
\text { educação } \\
\text { (SCHEIBE, 2010) }\end{array}$ & $\begin{array}{l}\text { Apresentar um } \\
\text { panorama das } \\
\text { ações voltadas à } \\
\text { formação docente } \\
\text { delineado a partir } \\
\text { do Plano de } \\
\text { Desenvolvimento } \\
\text { da Educação } \\
\text { (PDE), lançado } \\
\text { pelo Governo } \\
\text { Federal em abril } \\
\text { de } 2007 \text {, no qual } \\
\text { essa formação } \\
\text { ocupa papel de } \\
\text { destaque. }\end{array}$ & $\begin{array}{l}\text { Pesquisa qualitativa } \\
\text { bibliográfica. }\end{array}$ & $\begin{array}{l}\text { A responsabilidade que hoje se } \\
\text { delegou à CAPES no sentido de } \\
\text { fomentar os processos de formação } \\
\text { inicial e continuada de professores } \\
\text { não se pode ter a pretensão de } \\
\text { desarticular a responsabilidade das } \\
\text { demais secretarias do MEC nas } \\
\text { ações necessárias, mas sim diminuir } \\
\text { a distância entre as condições de } \\
\text { formação, desenvolvimento } \\
\text { profissional } \\
\text { e envolvimento com as pesquisas } \\
\text { existentes, e que são extremamente } \\
\text { diferentes na carreira da educação } \\
\text { básica em relação ao que ocorre na } \\
\text { carreira do ensino superior. O Plano } \\
\text { de Desenvolvimento da Educação } \\
\text { (PDE), tem certamente um grande } \\
\text { desafio a cumprir no que diz } \\
\text { respeito à formação docente para a } \\
\text { escolarização básica, o que significa } \\
\text { reconhecer o seu inter- } \\
\text { relacionamento com os diversos } \\
\text { campos que implicam hoje no } \\
\text { desenvolvimento educacional. }\end{array}$ \\
\hline $\begin{array}{l}\text { Institucionalização } \\
\text { da Educação a } \\
\text { Distância no } \\
\text { Instituto Federal } \\
\text { do Espírito Santo } \\
\text { (NUNES; } \\
\text { PASSOS; } \\
\text { SONDERMANN, } \\
\text { 2015) }\end{array}$ & $\begin{array}{l}\text { Descrever a } \\
\text { trajetória em } \\
\text { busca da } \\
\text { institucionalizaçã } \\
\text { o da Educação a } \\
\text { Distância, a partir } \\
\text { dos programas } \\
\text { Universidade } \\
\text { Aberta do Brasil } \\
\text { e Rede e-TEC } \\
\text { até a criação do } \\
\text { Centro de } \\
\text { Referência em } \\
\text { Formação e em } \\
\text { Educação a } \\
\text { Distância do } \\
\text { Instituto Federal }\end{array}$ & $\begin{array}{l}\text { Pesquisa Descritiva } \\
\text { através de pesquisa } \\
\text { documental e de } \\
\text { estudo de caso, } \\
\text { sobre o processo } \\
\text { de formação } \\
\text { estrutura } \\
\text { organizacional, as } \\
\text { políticas públicas } \\
\text { envolvidas, os } \\
\text { pressupostos } \\
\text { teóricos nos quais } \\
\text { se baseia o Cefor, } \\
\text { bem como os } \\
\text { desafios em sua } \\
\text { gestão. } \\
\text { Portanto, a mesma }\end{array}$ & $\begin{array}{l}\text { Destaca-se a importância da gestão } \\
\text { da Educação a Distância, para o } \\
\text { apoio aos campi da } \\
\text { instituição no que se refere aos } \\
\text { cursos a distância, ao uso de } \\
\text { tecnologias na educação e a } \\
\text { necessidade de ofertar cursos em } \\
\text { diferentes níveis e modalidades, } \\
\text { para atender a necessidade de } \\
\text { formação docente e dos } \\
\text { profissionais que atuam na } \\
\text { educação.A necessidade de uma } \\
\text { política em âmbito nacional para } \\
\text { institucionalização da Educação a } \\
\text { Distância, também foi observada, } \\
\text { dentre elas, a atividade de tutoria, } \\
\text { manutenção de polos de apoio }\end{array}$ \\
\hline
\end{tabular}




\begin{tabular}{|l|l|l|l|}
\hline do Espírito Santo. & $\begin{array}{l}\text { apresenta } \\
\text { abordagem } \\
\text { qualitativa, com } \\
\text { objeto de estudo } \\
\text { sendo o Instituto } \\
\end{array}$ & $\begin{array}{l}\text { presencial, infraestrutura para } \\
\text { composição do Centro de } \\
\text { Referência em Formação e em } \\
\text { Educação a Distância, respeito às } \\
\text { Santol do Espírito }\end{array}$ & $\begin{array}{l}\text { diferentes metodologia de Educação } \\
\text { a Distância e de definição de custo- } \\
\text { aluno da modalidade a distância. }\end{array}$ \\
\hline
\end{tabular}

A ampliação da discussão acerca das tecnologias educacionais aliada à formação docente possibilitou o incremento de produções acadêmicas que vão desde a renovação de metodologias pedagógicas, com propostas de atividades formativas para alunos, professores e gestão escolar, utilização de recursos tecnológicos em sala, de forma instrumental, assistiva e construtiva, à difusão da pesquisa e da ciência relacionada ao cotidiano, partindo da visão multiplicadora de conhecimento.

Viana Neto e Sarmento (2018) ao trazerem a questão das Webquest na formação continuada da EPT, reverberam os primeiros resultados das pesquisas realizadas no âmbito do Mestrado Profissional em Educação Profissional e Tecnológica - ProfEPT, dentre as quais este estudo também faz parte, evidenciando inquietações dos investigadores pertencentes ao programa para a formação de professores e as tecnologias educacionais. Os autores consideram ser a WebQuest "ferramenta com propósitos de orientar a busca de conhecimentos, em que parte ou todas as informações lá constantes e colocadas à disposição do estudante provêm da internet, previamente organizadas" (Dodge, 1995 apud Viana Neto e Sarmento, 2018, p. 03). Os autores destacam a gama de possibilidades e contribuições do recurso para a interdisciplinaridade, aprendizagem colaborativa, construção do conhecimento e motivação dos estudantes. Viana Neto e Sarmento (2018) discutem a formação de professores, destacando teóricos como Moura (2014), Machado (2008), Aranha (2008), Carvalho e Souza (2014) que destacam a necessidade de uma formação para a Educação Profissional e Tecnológica calcada na compreensão da educação em seu contexto, do mundo do trabalho e que perpassa a compreensão da práxis. Os autores concluem, a partir da revisão bibliográfica, que as TICs, neste estudo se referindo à WebQuest, possui efetividade, no entanto, não pode ser vista como ferramenta auxiliar, mas sim como proposta de transformação e autonomia.

Trevisol, Crescêncio e Domingues (2016), ao discutirem as tecnologias educacionais, tratam do uso da lousa digital interativa enquanto método de ensino e aprendizagem no Instituto Federal de Santa Catarina. $O$ estudo revela a ausência de formação dos docentes para o uso do referido recurso, ao mesmo tempo em que os participantes da pesquisa reconhecem a sua necessidade, bem como a importância das TICs na interação entre o professor e o aluno e na construção do conhecimento como facilitador do processo.

Com base na Aprendizagem Movida por Dados, Silva e Coelho (2017), trazem uma proposta de uso do software AntConc como possibilidade de utilização de estratégias tecnológicas voltadas ao ensino e a aprendizagem da Língua Portuguesa. Os autores atuam em Institutos Federais e em seu artigo de caráter tutorial, exploram o uso do software, suas 
funcionalidades e contribuições para a prática docente. Para os autores, o uso do material autêntico promove o desenvolvimento da autonomia e do envolvimento na análise de dados empíricos no campo da língua portuguesa. A compreensão pelos professores de como se utilizar as ferramentas do AntConc aliada à base teórica que a respalda, podem levar os estudantes ao protagonismo em sua busca pelo conhecimento.

Freitas e Duarte Filho (2018), apontam, que os professores conhecem e utilizam as TICs e o uso da aprendizagem móvel, através da dee learning (aprendizagem por meio eletrônico) ainda de maneira tímida, inatingindo 0 total potencial das ferramentas, necessitando de um aprofundamento no conhecimento dos recursos, funcionalidades e potencialidades do uso das TICs, para atingir a dee learning. Para isso, faz-se necessário o apoio da gestão escolar e a formação dos docentes e discentes para utilização satisfatória desses recursos, promovendo melhorias no processo de ensino e aprendizagem.

A baixa utilização das TICs pelos docentes pode ser explicada na pesquisa de Weizenmann, Jardim e Rocha (2014), intitulada "Os recursos tecnológicos utilizados pelos alunos do PEG". Nesta pesquisa, os docentes matriculados no programa de formação de professores para a educação profissional da UFMS foram questionados sobre a frequência na utilização de dispositivos eletrônicos e quais seriam esses dispositivos, apontando o resultado para acesso diário em email, redes sociais, ebooks, e vídeos através de notebooks, celulares, tablets e desktops. Desta forma, o apontamento dado pelo autor é de que apesar da frequência alta na utilização de recursos tecnológicos, os mesmos não são explorados em toda sua totalidade, e a medida necessária para minimizar a perda de potencialidade dos recursos sendo a formação docente.

Jardim, juntamente com Souza (2018), tratarão em seu estudo sobre o trabalho docente e o uso das tecnologias educacionais no âmbito da educação à distância em um curso lato sensu ofertado no Instituto Federal do Norte de Minas Gerais (IFNMG). Para o trabalho, as autoras trazem teóricos como Zabala (1998), Nóvoa (2010), Lévy (2003) (2007), Moran (2002), Libâneo (2009), dentre outros e trazem como resultados que a oferta de educação de qualidade requer profissionais qualificados, além de uma atuação docente compartilhada, com tempos e espaços de comunicação e participação do grupo. Compreendem, as autoras, a importância da formação no espaço do trabalho docente, considerando os conhecimentos já construídos, com capacitações e melhorias no currículo da EaD.

Lemos e Vieira (2010) partem para um estudo teórico que discute a importância da educação tecnológica em sua relação com a formação docente. As autoras destacam, assim, o papel de protagonista do professor em meio às constantes transformações que impactam na educação, sobretudo, a educação escolar a qual está incumbido o papel de atender às demandas do trabalho e propiciar um conhecimento amplo e cidadão. Nesta formação uma "tensão se impõe entre formar recursos humanos, orientandose para o mercado de trabalho, e formar cidadãos, a partir da educação voltada para uma democracia social e econômica (LEMOS, VIEIRA, 2010, p. 58). Assim sendo, as autoras concluem pela necessária formação de 
professores, amparada por políticas públicas, assim como planos de carreiras e salários que envolvam estes profissionais e suas entidades representativas.

Nesse mesmo sentido, também compreendem Brignoni e Pires (2010), ao constatarem que a formação de professores para a educação profissional é marcada por políticas emergenciais que saem de sua provisoriedade para se tornarem medidas efetivas. Ao analisarem as licenciaturas no contexto dos Institutos Federais deflagram um aumento na oferta destes cursos, entretanto ressaltam a necessidade de políticas públicas a fim de elevar a qualidade de ensino ofertada, bem como a valorização da formação continuada, da pesquisa e da graduação.

A investigação proposta por Conte e Ourique (2018), traz uma grande contribuição ao tratar dos sentidos e significados das tecnologias educacionais, seus impactos na atuação pedagógica e na compreensão dos processos de ensinar e aprender com o uso de recursos tecnológicos. $O$ estudo foi realizado a partir de um mapeamento na Biblioteca Digital Brasileira de Teses e Dissertações (BDTD) no triênio de 2012-2014 que embora não foque em determinados níveis e modalidades de ensino, traz abordagens, dentre as quais aparecem as políticas de formação dos Institutos Federais e a docência da educação profissional e tecnológica.

Nota-se nas teses a problemática da formação inicial e a continuada de professores para o uso das TICs. Além disso, os estudos revelam que "muitos professores das áreas técnicas desconhecem as potencialidades das tecnologias integradas à educação, bem como ignoram a legislação da EaD, que apregoa a reconstrução de atividades para os contextos de ciberpesquisa" (CONTE; OURIQUE, 2018, p. 07). Assim sendo, os resultados, constatados a partir das quatorze teses sob a abordagem analisada, trazem "a legislação e o planejamento de iniciativas tecnológicas para a educação profissional e inserção no mundo do trabalho" (CONTE; OURIQUE, 2018, p. 07).

A investigação proposta pelas autoras traz a relevância do trabalho na busca da compreensão dos sentidos e significados das tecnologias e suas ambiguidades reveladas que são,

fruto dos diversos enfoques acerca das tecnologias e suas linguagens, práticas e políticas, gerando perplexidades e incertezas no trânsito entre virtualidade e realidade pedagógica, e correndo o risco de recair na esterilidade do debate. (CONTE; OURIQUE, 2018, p. 01).

Para Koscianski; Silveira e Sauer $(2016$, p.127), a realidade pedagógica atual é de que o ensino deve transpor a memorização de elementos, partindo para uma reflexão crítica acerca da ciência e tecnologia encontradas no cotidiano do aluno, dando aplicação prática à ciência, proporcionando, desta forma, maior envolvimentos dos participantes do processo educacional e consequentemente maior conscientização de temas sociais e relevante transformação social.

A ressignificação do processo de ensino - aprendizagem, necessária na era tecnológica em que vivemos, possibilita a aquisição de novas 
habilidades que vão além do conhecimento cognitivo concebido, habilidades necessárias para o convívio social, ampliação da reflexão e crítica necessárias para se alcançar a cidadania são trazidas pelo processo de ensino tecnológico.

Com base no ensino regular presencial, o ensino a distância também comporta a aquisição de novas habilidades, onde o professor/tutor necessita de conhecimento das tecnologias existentes, sendo ferramentas imprescindíveis no ensino $\mathrm{EaD}$, além de grande usabilidade didática, planejamento, habilidades comunicacionais e todas as outras habilidades inerentes ao labor docente, não devendo portanto, existir distinção entre o tutor e o docente, conforme Gomes (2010, p.27).

Para Alves, (2002, p.48), um fenômeno chamado de turbulência é provocado pela introdução de novas tecnologias de formas sucessivas, causando uma desregulação no campo educacional, onde os tempos individual e coletivo são acelerados, impondo reajustamento de valores e de comportamentos. Desta forma, é imprescindível promover o acesso à infoalfabetização e à info-competência de maneira universal a todos os docentes, e uma das formas de conquista da universalidade de formação docente está relacionado com a educação à distância, no entanto, não basta ter acesso às tecnologias, o professor tem que querer modificar suas práticas pedagógicas, ajustando-as para se adequar ao novo contexto tecnológico.

Oliveira; Abreu, Gomes (2015), através de um curso de recursos educacionais abertos, propõe uma alternativa para a formação continuada docente à distância. Para isso sugere o uso de repositórios online na busca de materiais que possam ser incluídos nas suas técnicas pedagógicas denominadas de Práticas Educacionais Abertas aliadas a outros métodos. Para os autores os recursos tecnológicos "oferecem maior versatilidade, interatividade e flexibilidade de tempo e de espaço no processo educacional" (p.101), corroborando com as falas de Alves (2002), Kenski (2013), já citados neste texto.

A maioria dos trabalhos apresentados apontam que a formação do professor é imprescindível neste novo contexto educacional em que vivemos, seu dinamismo exige o mesmo movimento enérgico dos docentes, na busca pelo conhecimento e pela adaptação metodológica necessária para a atuação plena deste profissional. Contudo Scheibe (2010, p.99), aponta para a necessidade da discussão para a obrigatoriedade dos órgãos públicos em promover a formação docente, de forma a cobrir as novas necessidades educacionais deste período, bem como investir nas diversas formas de valorização docente e condições das escolas.

Os apontamentos de Scheibe (2010) exprimem a necessidade de formação e valorização dos profissionais da educação e o grande desafio do Plano de Desenvolvimento da Educação (PDE) para o cumprimento das metas educacionais, tomando como base o assunto aqui discutido. Desta forma, a autora sugere o encaminhamento de sugestões "de forma organizada e participativa, abrangendo as entidades e as associações acadêmicas e científicas, assim como o conjunto das nossas instituições educacionais" (p.106), para viabilizar uma formação de qualidade aos profissionais da educação. 
Neste sentido, Nunes; Passos e Sondermann (2015), explanam sobre a experiência em implantar um Centro de Referência em Formação e em Educação a Distância do Instituto Federal do Espírito Santo, visando a formação docente e demais servidores. Explicitam, ainda, sobre a complexidade de gestão e organização de um processo educacional a distância e de qualidade. Partindo dos parâmetros legais que institucionalizaram a Universidade Aberta do Brasil e da Escola Técnica Aberta do Brasil, o Cefor se tornou centro de referência em educação a distância, ofertando cursos superiores, de graduação e pós graduação lato e stricto sensu.

Com base nos estudos vistos, percebe-se que a formação docente, relacionada ao uso das tecnologias em sala de aula, deve ser precedida de uma legislação que compreenda não só a formação do profissional, mas que possibilite uma estrutura organizacional que ampare a formação do professor. Da mesma forma, a equipe de gestão deve se fazer presente, viabilizando e oportunizando novas práticas e a partir da recepção das condições necessárias, o professor deve fazer uso da criatividade e as tecnologias disponíveis para fazer pontes associativas entre o conhecimento prévio e o novo, entre a ciência e a vida cotidiana, tornando concreto e real o conhecimento que antes era afastado do mundo de pertencimento do aluno.

\section{CONSIDERAÇÕES FINAIS}

O presente estudo permitiu uma análise do cenário da produção científica no período de 2010 a 2018 que versa sobre as tecnologias educacionais e seu entrelaçamento com a formação de professores no âmbito da educação profissional e tecnológica. Ao encontro da necessidade de formação dos que atuam na Rede Federal de Educação Profissional, Científica e Tecnológica, e não só a ela limitada, os resultados vêm demonstrando um campo sedento de investigações voltadas à EPT que tragam contribuições para essa área de atuação.

E para que propostas de formação na EPT possam ser acompanhadas com qualidade social, este trabalho coaduna com o que postulam Conte e Ourique (2018), ao considerarem a tecnologia em seu sentido mais profundo, enquanto ação política. Sabe-se que frente às inovações tecnológicas suas transformações geram contradições e resistências, que, por sua vez, permitem criar condições para novas formas de ação. Sendo assim, no contexto educacional, o diálogo pedagógico deve se orientar contra a alienação e a uniformidade dos conhecimentos. Para Moura (2008), trata-se, ao final, da construção por uma sociedade "na qual a tecnologia esteja submetida a uma racionalidade ética em vez de estar a serviço exclusivo do mercado e do fortalecimento dos indicadores econômicos (MOURA, 2008, p. 197).

E por assim ser, esta discussão traz o olhar para um personagem fundamental no processo formativo e sobre ele as múltiplas forças em disputa: o professor e, neste estudo, sua formação no contexto da EPT. Sob cautela de que não lhe recaia unicamente toda a sorte de sucesso ou fracasso escolar, o docente está sendo constantemente confrontado 
sobretudo pela sua atuação diante dos desafios da época, dentre eles, as novas tecnologias da informação "e a lógica da produtividade e mercado que estão definindo os valores da política educacional e até da cultura ocidental contemporânea" (CUNHA et al., 2005, p. 06). Sendo assim, alertam os autores para necessidade de se trazer junto da profissionalização docente 0 contexto político-econômico na qual ela está inserida.

Por isso, tão recorrente nos estudos analisados é a compreensão de que a formação docente precisa estar amparada por sólidas políticas públicas e não como medida emergencial e fragmentada como vem sendo tratada em seu percurso histórico. Calcada no contexto em que é produzida e com leitura das relações entre trabalho e educação, a formação docente precisa compreender também a tecnologia como produção humana e dela não se desvencilhar, imersa em espaços e tempos de construção compartilhada de reflexão da atuação na EPT.

É necessário, portanto, avançar em propostas de formação humana e formação docente atreladas à educação profissional e tecnológica, trazendo para o uso das tecnologias educacionais seu caráter social e sobre elas avançar na proposição de uma formação integral e emancipatória.

\section{REFERÊNCIAS}

ALVES, Israel Gutemberg. As novas tendências da formação de professores no contexto tecnológico. Revista Educ. Tecnol., Belo Horizonte, v.7, n.2, p.46-53, jul./dez. 2002. Disponível em < https://periodicos.cefetmg.br/index.php/revista-et/article/view/45> Acesso em 04 nov. 2018

BRIGNONI, C. P; PIRES, L. L. A. A formação de professores para a educação profissional nos Institutos Federais. $7^{\text {a }}$ Semana de Licenciatura: Educação Científica e Tecnológica: Formação, Pesquisa e Carreira. IFGO. Jataí: 2010. Disponível em <http://sam.ifgoias.edu.br/jatai/semlic/seer/index.php/anais/article/view/78/trab completo10> Acesso em 06 nov. 2018.

CERVO, A. L.; BERVIAN, P. A.; SILVA, R. da. Metodologia científica. 6. ed. São Paulo: Pearson Prentice Hall, 2007.

CONTE, E; OURIQUE, M. L. H. Interlocuções das pesquisas em tecnologias na educação. Revista Educ. Pesqui., São Paulo, v. 44, e168214, 2018. Disponível em <http://www.journals.usp.br/ep/article/view/144805/139049> Acesso em 06 nov. 2018.

CUNHA et al. As políticas públicas de avaliação e docência. Impactos e repercussões. In: CUNHA, M. I. (Org). Formatos avaliativos e concepção de docência. Campinas, SP: Autores Associados, 2005. - (Coleção educação contemporânea).

FREIRE, P. Pedagogia da autonomia: saberes necessários à prática educativa. São Paulo: Paz e Terra, 1996. 
FREITAS, Priscila Cabreira de; DUARTE FILHO, Nemésio Freitas. Aprendizagem móvel: percepções quanto à utilização por docentes da educação profissional e tecnológica. Revista Educação a distância e Práticas Educativas Comunicacionais e Interculturais. São Cristóvão (SE) v.18. n. 2, p. 50-63 mai./ago. 2018. Disponível em <https://seer.ufs.br/index.php/edapeci/article/view/8568> Acesso em 01 nov. 2018.

GOMES, Ednaldo Farias. Perfil e identidade do tutor em cursos na modalidade a distância do IFAL vinculados ao Sistema Universidade Aberta do Brasil: definições e prática docente. Revista Eletrônica Multidisciplinar Pindorama do Instituto Federal de Educação, Ciência e Tecnologia da Bahia - IFBA, no 01 - Ano I - Agosto/2010. Disponível em <https://publicacoes.ifba.edu.br/index.php/Pindorama/article/view/370> Acesso em 04 nov. 2018.

KENSKI, V. M. Tecnologias e tempo docente. Campinas, SP: Papirus, 2013.

KOSCIANSKI, Patrícia Vanat; SILVEIRA, Rosemari Monteiro Castilho Foggiatto; SAUER, Elenise. Substâncias \& Cotidiano: uma proposta para o ensino de ligações químicas por meio do enfoque ciência, tecnologia e sociedade. In. Reflexões em ensino de Ciência e Tecnologia: abrindo horizontes. / Antonio Carlos Frasson ... [et al.] (org.). - Curitiba: Ed. UTFPR, $2016 . \quad$ Disponível em< http://riut.utfpr.edu.br/jspui/bitstream/1/2051/7/reflexoesensinodeciencia.pdf\#p age $=87>$. Acesso em 10 nov. 2018.

LEMOS, R. M; VIEIRA, V.M. O. Educação tecnológica e formação docente: saberes e práticas em foco. Revista Profissão Docente, Uberaba, v.10, n. 21, p. 51-60, jan/jun. 2010. Disponível em <http://revistas.uniube.br/index.php/rpd/article/view/208/1138>. Acesso em 06 nov. 2018.

MOURA, D. H. A formação docente para uma educação profissional e tecnológica socialmente produtiva. In: BRASIL. Formação de Professores para Educação Profissional e Tecnológica. Brasília: INEP, 2008, p. 193223. (Coleção Educação Superior em Debate, 8). Disponível em: $<$ http://inep.gov.br/informacao-da-publicacao/-

/asset_publisher/6JYIsGMAMkW1/document/id/492287>. Acesso em: 01 nov. 2018.

Trabalho e formação docente na educação profissional. Curitiba: Instituto Federal do Paraná, 2014 - (Coleção formação pedagógica; v. 3). Disponível em <http://curitiba.ifpr.edu.br/wpcontent/uploads/2016/05/Trabalho-e-Forma\%C3\%A7\%C3\%A3o-

Docente.pdf>. Acesso em 25 nov. 2018.

NUNES, Vanessa Battestin; PASSOS,Marize Lyra Silva; SONDERMANN, Danielli Veiga Carneiro. Institucionalização da Educação a Distância no Instituto Federal do Espírito Santo. 2015. Disponível em < http://www.abed.org.br/congresso2015/anais/pdf/BD_271.pdf> Acesso em 03 nov. 2018.

OLIVEIRA, Francisco Kelsen de; ABREU, Kélvya Freitas; GOMES, Antônio 
Anderson da Silva. Formação profissional em Recursos Educacionais Abertos. Revista Semiárido De Visu, v. 3, n. 2, p.98-109, 2015. Disponível em $<\mathrm{https}: / /$ periodicos.ifsertaope.edu.br/ojs2/index.php/revista/article/download/205/132>. Acesso em 07 nov.2018.

PACHECO, E. M.; MORIGI, V. (Org.). Ensino Técnico, Formação Profissional e Cidadania: a revolução da Educação Profissional e Tecnológica no Brasil. Porto Alegre: Tekne, 2012.

QUARTIERO, E. M; LUNARDI, G. M. BIANCHETTI, L. Técnica e tecnologia: aspectos conceituais e implicações educacionais. In: MOLL et al. (Orgs). Educação Profissional e Tecnológica no Brasil contemporâneo. Desafios, tensões e possibilidades. Artmed, 2010.

SCHEIBE, Leda. Políticas públicas de formação docente: o desafio do direito à educação. Revista Ensino Em-Revista, Uberlândia, v.17, n.1, p. 95109, jan./jun.2010. Disponível em < http://www.seer.ufu.br/index.php/emrevista/article/download/8186/5198> Acesso em 10 nov. 2018.

SILVA, R. G; COELHO, I. M. W. S. O uso de recursos tecnológicos para o ensino de Língua Portuguesa: proposta de utilização do Software AntConc. III Simpósio em Ensino Tecnológico no Amazonas (SETA 2017). Disponível em <http://mpet.ifam.edu.br/wp_seta/wpcontent/uploads/2016/07/Anais_Seta-2017.pdf\#page=91> Acesso em 12 nov. 2018.

SOUZA, W. S. S. S; JARDIM, S. R. A organização da docência coletiva no contexto da educação a distância: o uso das tecnologias de informação e comunicação e a ação pedagógica. Multifaces / v. 1, n. 1, abril, 2018, p. $1-14$. Disponível em <http://multifaces.ifnmg.edu.br/index.php/multifaces/article/view/99/>. Acesso em 12 nov. 2018.

TREVISOL N. P; CRESCÊNCIO, M; DOMINGUES, M. J. C. S. O uso da lousa digital interativa pelos docentes de um instituto federal (SC). Revista GUAL, Florianópolis, v. 9, n. 1, p. 120-142, jan. 2016. Disponível em $<$ https://periodicos.ufsc.br/index.php/gual/article/view/19834535.2016v9n1p120/31556> Acess. 06 nov. 2018.

VIANA NETO, A. A.; SARMENTO, J. N. P. WebQuest na formação continuada de professores da Educação Profissional e Tecnológica. $2018 . \quad$ Disponível em <http://cietenped.ufscar.br/submissao/index.php/2018/article/view/636/431>. Acesso em 10 nov. 2018.

WEIZENMANN, Carlos Eduardo; JARDIM, Rafaela;ROCHA, Karla Marques da. Os recursos tecnológicos utilizados pelos alunos do PEG. $7^{\circ}$ Jornada Acadêmica do Curso de Educação Física, 2014. Disponível em <http://fames.edu.br/jornada-academica-educacao-fisica-da-fames/anais/7ajornada/carlos-weizenmann-recursos-tecnologicos-ufsm.pdf> Acesso em 10 nov. 2018. 